\title{
CENTENARIO DEL NACIMIENTO DE JORGE BASADRE GROHMANN
}

Discurso pronunciado por el Historiador Percy Cayo Córdova en el Congreso de la
República, con ocasión del centenario del nacimiento del Doctor Jorge Basadre Grohmann,
Historiador de la República.

Percy Cayo Córdova (1937-2004). Historiador. Dictó conferencias en universidades peruanas extranjeras. Fue catedrático en la Universidad de Lima, en la Pontificia Universidad Católica del Perú y en la Universidad del Pacífico a la que donó su biblioteca. Fue miembro de número en la Academia Peruana de la Historia y en el Instituto de Estudios Históricos-Marítimos. Entre otras condecoraciones el gobierno peruano le otorgó la Orden al Mérito en el Grado de Gran Cruz. Integró la delegación que firmó la PAZ DE BRASILIA (1998) con la república del Ecuador. Tacneñista y basadrino de nota. Autor de más de quince libros de su especialidad. 
SI MI INFANCIA EN TACNA ME ENSEÑÓ DOLOROSAMENTE LA EMOCIÓN DEL PERÚ Y LA BIBLIOTECA NACIONAL ME PERMITIÓ CULTIVAR DESDE MUY JOVEN LOS ESTUDIOS HISTÓRICOS, EL OTROFACTOR DECISIVO PARA MI MOCEDAD FUE LA INQUIETUD SOCIAL DE LA QUE ME CONTAGIE EN LOS CLAUSTROS DE LA UNIVERSIDAD DE SAN MARCOS ENTRE 1919 Y 1927.

He querido iniciar mis palabras usando como epígrafe el texto poco conocido de don Jorge Basadre, "Perú Vivo" de 1966.

En el que queda más que justificada la presencia de quienes me han antecedido en el uso de la palabra; por la Biblioteca Nacional su Director, en donde nos dice nuestro homenajeado cultivó desde muy temprano "los estudios históricos"; y por San Marcos su Rector, en donde se contagió de la "inquietud social".

Junto a estas dos instituciones menciona el Historiador de la República a Tacna, de la que proclama "me enseñó dolorosamente la emoción del Perú".

Alto honor se me confiere este medio día al hacer uso de la palabra - en representación que abruma - en el Homenaje que la Nación, por medio del Congreso de la República, rinde a don Jorge Basadre en el centenario de su Nacimiento.

Queda claro lo legítimo que resulta incorporar en este homenaje, el tema de Basadre y Tacna, pues bien sabemos la entrañable relación que hubo entre el Historiador de la República y su ciudad natal, Tacna, la vieja Tácana, como la menciona Luis Cavagnaro, notable historiador discípulo predilecto de don Jorge en tal quehacer en la heroica ciudad.

Tal vez no sea exagerado decir que muy pocas personalidades prominentes - o tal vez ninguna - en nuestra historia, haya proclamado tanto, ni tan reiteradamente y con tanta devoción, su entrañable vínculo con su lar nativo.

¿Qué razones podríamos encontrar para ello, más allá del natural amor que convoca comúnmente el suelo natal?

Creemos que por allí figuran las características excepcionales que encerraba la tierra en que don Jorge vió la luz primera. Bien lo sabemos, nació hace 100 años, 1903, en tierra ocupada. Esa desgracia debió fortalecer la ligazón que el recuerdo propiciaba, al hablar de épocas - que duda cabe - mejores para ese entrañable espacio de la Patria. No calló, más bien pregonó don Jorge Basadre, sus remotos vínculos con Tacna.Sus antepasados por vía paterna y materna.

Realzó sus ancestros remontándolos hasta los Ara. Fueron sus palabras:

"lejos de cualquier alarde, señalo que nuestra familia puede jactarse de un complejo abolengo peruano republicano con vertientes emanadas desde los más diversos y antagónicos orígenes".

No caeremos en afanes genealógicos pero bastaría repetir con el maestro tacneño: "Carlos Basadre Izarnótegui - nos dice - tuvo por esposa a Concepción Forero y Ara..."

Más cedamos la palabra al propio maestro: "Por el lado de mi abuela materna Ara, descendemos de indios ligados a nuestro terruño durante muchas centurias. Mis bisabuelos paternos Basadre y Belaunde, representan la herencia española, proveniente del virreinato. Mi bisabuelo paterno, Forero, encarna la época de la independencia del Perú. En los nombres Izarnótegui y Rosales hállase la sangre común americana que en otros parientes y relacionados contemporáneos se ha esparcido 
nuevamente a los países vecinos. Los apellidos Grohman (alemán) y Butler (irlandés), simbolizan los modernos pobladores europeos que, sin peligrosos separatismos, vinieron a fundar hogares en estas tierras y a colaborar en comunes tareas, de acuerdo con el mensaje promisorio que el continente americano ha significado para millones de hombres y mujeres desde el siglo XVI".

Por cierto que no postergó el reconocimiento a sus ancestros maternos; debió frecuentar en su hogar el uso del idioma alemán, lo que explica cómo pudo incorporarse sin dificultades mayores al llegar a Lima, a los 12 años de edad, en el Colegio Alemán, donde, por otra propia confesión, recordaría que salvo los cursos de Historia del Perú, Castellano - que obvio - y Religión, todos los demás eran dictados en aquel idioma.

Teniendo seis años, en 1909 Basadre había vivido la penosa experiencia de la muerte de su padre Carlos Basadre y Forero; sus recuerdos tienden desde entonces a ser mayores. Un drama familiar subsistía detrás de tal desaparición: quedaban la viuda Olga Grohman Pividal y sus siete hijos de los que Jorge - al que evocamos este mediodía -, era el menor.

Del padre sabemos que era ingeniero y que por haber estado en la capital, no participaría en las acciones de Tacna y Arica a mediados de 1880, pero que sí había combatido en Miraflores.

En esta época de horarios corridos y de omnipresente televisión, resulta muy distante evocar, reconstruir, como debieron ser los tiempos inmediatamente posteriores a aquella ausencia paterna. Más aún en época en la que el duelo es tan sólo un recuerdo, resulta impensable el quehacer de un niño durante el prolongado período de luto "tan riguroso en la vida provinciana", como lo recuerda nuestro homenajeado.

Debió entonces zambullirse en la lectura. El niño que se abre a la juventud, debió asomar a la importante biblioteca paterna. En ella debían prevalecer los textos de Historia.

Sabemos que sus ancestros tacneños habían tenido una particular devoción por la historia:- Su abuelo Carlos Basadre Izarnótegui, que casó con Concepción Forero y Ara, como hemos recordado, fue autor de "Apuntes sobre la Provincia de Tacna", publicados en la notable Revista de Lima entre los años 1862 y 1863, "primer estudio sobre la geografía e historia de Tacna", a decir de sus notable nieto. Son más conocidos los trabajos del tío bisabuelo, Modesto Basadre y Chocano, quien publicó sin secuencia cronológica en el diario La Patria entre enero de 1877 y el mismo mes de 1878 , nueve colaboraciones.

Estos artículos fueron editados como parte de la Biblioteca de la República que Jorge Basadre y Félix Denegri dieron vida a mediados del pasado siglo. Mas hubo otro trabajo fundamental que editó don Modẹsto Basadre en 1860 y que tituló Refutación Documentada, del folleto titulado Cuestión de Límites entre Ecuador y el Perú, publicado en Santiago de Chile por P.M. que bien sabemos era Pedro Moncayo. En otro lugar hemos estudiado el enorme valor de este trabajo que, aún en su brevedad, fue pionero en rebatir ciertas tesis de nuestro vecino septentrional que a pesar de tan vigorosa refutación, se mantuvieron como tales hasta los días de la culminación del contencioso limítrofe, hoy felizmente superado.

De la numerosa Biblioteca paterna - testimonio de que sus mayores fueron gentes afectas a la lectura - podemos deducir que allí - en el lar tacneño - le brotaría lo que el Maestro llamaría "el vicio impune de leer", que bien sabemos cultivo sin jac- 
tancia. Ciertamente la vieja ciudad debía serle propicia; la provincia reposada y gentes de antepasados vinculados a su historia - como actores o autores de relatos de los mismos - ; en verdad tal ambiente convidaba a la lectura.

Podríamos añadir, en esta relación íntima entre el historiador y su tierra - que ésta, su amada Tacna, era propicia cuna de historiadores: no es impertinente mencionar a don Carlos Wiesse, quien fue - para su época - autor de excelentes textos de historia patria.

El nombre de Manuel de Mendiburu también está vinculado a la tierra tacneña y aunque bien sabemos que no nació en ella, despertó notable admiración por su magnífico desempeño como Prefecto; de él diría don Jorge Basadre "En mi infancia y posteriormente escuché de unos viejos la evocación de aquellos tiempos que .... estaban olvidados ... Era, una que otra vez, el homenaje a los grandes prefectos que Tacna había tenido, como el general Manuel de Mendiburu, a quien -añade nuestro homenajeado - se debiera El mensajero de Tacna, primer periódico de la ciudad, el empedrado del río Caplina en la zona urbana y muchas otras mejoras". Bien sabemos que ya no en esa dimensión provincial, sino en la nacional, el Perú es deudor a Mendiburu del soberbio Diccionario Histórico - Biográfico del Perú, que lo constituye como el mayor de los historiadores del siglo XIX.

Sería impertinente prolongar con nuevas nominaciones este humus telúrico de Tacna por la historia; mencionar a Zora Carbajal, Guillermo Auza Arce y otros, solo sería mostrar que la lista siempre podría ser bastante más amplia, si se trata de no dejar de mencionar a ninguno. Siempre queda incompleta la relación, mas juzgo indebido no mencionar a Rómulo Cuneo Vidal, autor de numerosos trabajos de Tacna y de quien no se puede prescindir si nos acercamos al estudio de las primeras insurrecciones tacneñas por la independencia, mas allá de su nacimiento en la vecina Arica.

Al evocar en La Vida y la Historia de la biblioteca paterna, recordaba Basadre: "juntas halle, aunque no pudiera inicialmente devorarlas, obras de grandes historiadores chilenos, bolivianos y peruanos del siglo XIX, los tomos de la biblioteca de escritores griegos y latinos publicada en España, el gran diccionario de Montaner y Simón, varias ediciones de Don Quijote de la Mancha y diversas obras de literatura española contemporánea, incluyendo las novelas de Pérez Galdós y Pereda".

Ciertamente las lecturas en la Biblioteca paterna en los últimos años de su presencia en Tacna, debieron quedar grabadas en su memoria.

En algún texto recordara a su profesor de Historia del Perú en el Colegio alemán, que no fuera oro que el poeta Alberto Ureta, a quien en alguna oportunidad sorprendería al "repetir las palabras de Prescott tomados de su obra sobre la Conquista del Perú que estaba en la colección de mi padre", según evoca.

Hasta donde alcanza nuestro quehacer en busca de los orígenes de la preocupación del ilustre tacneño por la historia, esta parece ser la primera referencia que hallamos a la lectura de un libro largo aliento y que, como bien sabemos, constituye obra clásica sobre la Conquista.

Debió llamar la atención entre sus compañeros del colegio alemán la presencia del joven tacneño; por aquellos años las noticias de desvaríos chilenos en Tacna, Arica y algo menos en Tarapacá, eran omnipresentes en los diarios capitalistas, y no solo en ellos; en particular desde los años previos de Basadre en su nuevo Colegio una cadena de noticias lamentables, tenían como escenario Tacna y Arica y ese joven 
y nuevo estudiante provenía de allí; él era -había sido- testigo de una tierra que mostraba tercamente su voluntad de seguir perteneciendo a la heredad nacional; para esos jóvenes no era tema ignorado que se había vencido el plazo que perentoriamente había ordenado el llamado Tratado de Ancón para la realización de un plebiscito, a través del cual quedaría expresada la voluntad ciudadana: Tacna y Arica debían reencontrarse con la nacionalidad que integraban.

La convicción de la derrota en el ordenado plebiscito hacia que le ocupante no solo negara su realización, sino que, por la violencia intimidadora, procurarse quebrar la voluntad patriótica de tacneños y ariqueños: así, ese joven recién integrado al plantel alemán, aparecía como un testimonio viviente de todo aquello que los periódicos traían día a día como prueba al patriotismo que resistía a la feroz violencia desatada por el indebido ocupante.

Es dable, por eso, imaginar que nuestro homenajeado participara con particular devoción en los actos históricos en que por entonces se evocara alguna efemérides patria; por aquellos días, acudiría a los actos convocados para conmemorar el cincuentenario de la acción naval del Callao el 2 de Mayo de 1916; igualmente del centenario de nacimiento de nacimiento de don Francisco Bolognesi, el 4 de noviembre del mismo año; tal también lo motivo el homenaje a Santa Rosa de Lima, en el tricentenario de su fallecimiento del 24 de agosto de 1917.

Mas la ecuación Tacna-Basadre alcanzaría cotas muy altas, al ingresar al último año de su escolaridad en el colegio Guadalupe. Tendría allí como profesor de Historia del Perú a don Adolfo Quiroga, al que califica de "capaz y bueno"; la materia de castellano la regentaba el profesor Arturo Montoya; en ella estaba incluida la historia literaria, que fue uno de sus descubrimientos en el ya viejo colegio. En alguna forma remembranza de aquellos días, Basadre trae la mención del descubrimiento del Elogio a Grau, de Manuel González Prada, texto que declara le causo particular emoción; lo leería en la Antología que completaba el texto escolar de Montoya.

No pasó desapercibido para el profesor Montoya, el particular interés que el joven tacneño mostraba por la temática histórica; no tenía ni dos meses en el viejo plantel y recibiría un singular encargo; por el propio Basadre nos enteramos que en aquellos años se acostumbraba que un alumno de Guadalupe pronunciara en la efemérides de la Batalla de Arica -7 de junio de cada año--, el discurso ante el monumento a don Francisco Bolognesi, inaugurado -para aquellos días -tan solo hacia menos de 13 años.

¿Qué llevaría a que un joven alumno, recién incorporado a aquellas aulas, fuese escogido entre los 42 miembros de su promoción, para tan significativo evento?

Evidentemente para nuestro homenajeado de este medio día debió constituir un reto enorme; acababa de cumplir los 15 años, y se le encargaba responsabilidad tan honrosa y difícil.

Habría que recordar que entonces -a tan solo 38 años de la acción habían muchos sobrevivientes y por cierto muchos descendientes de quienes ofrendaron la vida en defensa de la Patria. Bueno es mencionar que aquel 7 de Junio de 1918 asistieron al acto de homenaje, Enrique, Augusto y Alberto Bolognesi, nietos del bizarro Jefe de la Plaza de Arica.

Aventurando, y dando vuelo a la imaginación, la razón que pudo pesar en el ánimo de quienes lo designaron, sería que el joven guardaba notables recuerdos del hecho. Podemos citar líneas de sus Recuerdos de Tacna, publicados en la Revista 
Fanal en 1953; allí decía: “Desde muy niño escuche el relato de episodios y anécdotas del pasado local y nacional. La parte más dramática y reiterada de esas evocaciones, se refería a la guerra del Pacífico, que entonces parecía un hecho cercano y obsesionante. Oí muchas veces como fueron las batallas de Tacna y el Combate de Arica"; allí mismo agrega: "evocaba mi madre a los jefes y oficiales que visitaban su casa antes de las batallas", ... a Ramón Zavala "también muy joven, muy rico y muerto en Arica"; a Roque Saenz Peña "el gallardo argentino de quien se decía que no solo el deseo de luchar por la justicia sino también un amor desgraciado lleváronle a ofrecer su espada al servicio del Perú"; a Gregorio Albarracín, apodado el Centauro de las Vilcas, al que menciona como "legendario" y agrega "que siguió luchando incesantemente después de la batalla de Tacna"; a Lizardo Montero al que moteja de "alegre Vice-almirante Comandante en Jefe del ejército peruano en esa batalla" (obviamente se refiere a la batalla de Tacna); al Prefecto Pedro Alejandrino de Solar; al alcalde Guillermo MacClean y otros.

Debía recordar con particular devoción la acción que tuvo como escenario el Morro, ara bendita de la Patria, pues allí dos de sus tíos -primos hermanos de su padre-, Federico y Armando Basadre Castañón, habían rendido la vida en esa epopeya tan singular de la guerra infausta.

Creemos con convicción que el tema de Arica - tan vinculada como ciudad y como espacio de heroicidad a Tacna-, debía cautivar al escolar tacneño del más antiguo plantel republicano, como acto heroico viril y por reminiscencias familiares.

Del discurso que pronunciara diría que fue "un conato de interpretación de la batalla en el morro de Arica". Lástima que esfuerzos realizado no nos llevaron al final feliz que sería hallar ese primer trabajo del historiador de la República.

Como si no fuera su corta edad reto suficiente -que en algo compensaba su peculiar conocimiento del acontecimiento entonces recordado-, éste se incrementaba por la circunstancia de que en Guadalupe enseñaba el curso de Física Teodoro Elmore, a quien Basadre recuerda como "viejecito menudo de barba cana y recortada, muy nervioso, lleno de vivacidad". Y añade nuestro historiador que "no dejaba de contar anécdotas de la defensa de Arica en 1880, en la que participó como ingeniero, hecho por el cual había recibido injustas acusaciones".

También enseñaba entonces en Guadalupe el sacerdote Vitaliano Berroa, quien en el ejercicio de su labor religiosa fue nombrado vicario de la iglesia de Tacna y Arica en 1904; por aquellos años ya Chile realizaba una muy dura acción antiperuana a la que Berroa hizo frente; ese notable sacerdote -increíblemente tan poco recordado -, cuando previó las acciones más duras que realizara el ocupante, logró poner a buen recaudo -salvar- los archivos parroquiales, que sirvieron más adelante para probar los derechos de los nativos de aquellas jurisdicciones, remitiéndolos al Ministerio de Relaciones Exteriores en Lima. Sus acciones en salvaguarda de la peruanidad, llevó a la desesperación a las autoridades de ocupación que luego de ingentes hostilizaciones terminaron por clausurar todas las Iglesias de Tacna y Arica y posteriormente expulsar a todos los curas; contra estas prepotentes ordenanzas litigó duramente Berroa, hasta que fue expulsado por orden expresa del Canciller chileno, el inefable Agustín Edwars.

Berroa en Guadalupe fue profesor de Fundamentos y Dogmas del Catolicismo y también de Matemáticas, ejerciendo de Capellán del Colegio cuando el joven culminaba sus estudios escolares. 
Hemos querido rastrear particularmente hasta los días finales de su escolaridad, la íntima relación entre Basadre y lar nativo, cuando ya vivía sus días capitalinos.

Sabemos bien que este estrecho vínculo se mantuvo tecamente a través del tiempo. La brevedad de unas palabras de homenaje y recuerdo, no permiten extendernos más de lo indispensable.

Lo que vino más tarde es mejor conocido, particularmente sus constantes escritos sobre su tierra; el primero que hemos hallado es de 1923, en Variedades. Cito sus palabras "Una campaña feraz donde se juntan la escasez de agua que obliga a establecer horarios en el regadío y la riqueza no igualada de frutas y legumbres, rodean a la muy noble y leal ciudad deSan Pedro de Tacna". Ese texto precedió al que se en esa misma revista, en muy distinta circunstancia escribiera en 1925, que título "El aroma del regreso", en que relata su emoción por el reencuentro con su ciudad en los días del frustrado plebiscito. Años más tarde, 1953, en Fanal editaría Recuerdos de Tacna, que amplió en su clásico Infancia en Tacna, de 1959, que con notables variaciones aparcería en La Vida y la Historia, en 1975 y aun con otras mayores en 1981. No es ese todo el periplo del tema tacneño de don Jorge, pero puede ser un eventual derrotero para quien desee internarse más a fondo en esa semblanza siempre amable con que presentó a su entrañable tierra nativa.

Muchos temas quedan en el tintero, o para evocación mayor; su tacneñismo fue perenne, $y$ tantas veces brotó al ocuparse de hechos y personajes de su terruño; tal sus recuerdos a su maestra Carlota Pinto, su nodriza Genoveva Salinas y su hermana Luisa, así como la remembranza de su admirado paisano Francisco de Paula Gonzáles Vigil, también su antecesor en la dirección de la Biblioteca Nacional.

A través de sus textos hallaremos numerosas menciones emocionadas y amables a espacios de su ciudad natal:

la Plaza de Armas, donde estaba avecindada su casa

la recova,

la pila, hermosa la llama, que adorna la ciudad

la Alameda, a la que no deja de calificar de linda o bella;

las acacias y los jacarandás,

los techos de mojinete,

los molles y las buganvilias,

la pequeñez del Caplina,

la camanchaca,

la pirámidenevada del Tacora,

sus excursiones a la boca del rio,

el empedrado del mismo,

la imagen infaltable de la inconclusa catedral,

y tantas menciones que evocaba cuando renovaba sus viejos recuerdos. No hay hipérbole en mis palabras, aunque dejo constancia que nunca estuve con don Jorge en la vieja ciudad sureña, más allí están los jóvenes de entonces que compartían sus gozosas breves estadías en la ciudad de sus amores y a los que contagio de sus afectos y hoy son quienes mejor podrían dar testimonio de ello: Grover Pango, Fredy Gambetta, el ya mencionado Luis Cavagnaro, Guido Fernández de Córdova, Virginia Lázaro, entre muchos otros.

Pero si no cabe extenderse más para mostrar los estrechos vínculos de Basadre y Tacna, Tacna y Basadre, no cabe prescindir de una de las últimas oportunidades en 
que expresó públicamente su preocupación por el lar nativo. No mencionaré el tan conocido y recordado texto del Cade 79, celebrado precisamente en Tacna y donde retomo el título de Perú "dulce y cruel", ya expresado con anterioridad.

Me refiero finalmente al discurso que pronunció cuando en enero de 1979 recibió la Orden del Sol. No cabe recordar lo muy tardío que llegaba tal presea al notable historiador. Sin duda su sola aceptación de la misma honraba a una Orden ya entonces -y hoy en día creemos mucho más-, lamentablemente desprovista de la prestancia que debía poseer por su mecánica repartición, que dista mucho de convertirla en homenaje excepcional como debiera ser.

Mas el tema son las palabras que dedicó a Tacna don Jorge aquel 26 de enero y que son un llamado de atención a la histórica postergación a esa tierra que sin alardes ha dado muestras hermosas de patriotismo.

SÉ QUE MIS PALABRAS ESTÁN SIENDO TRANSMITIDAS A LO LARGOY ANCHO DEL TERRITORIO NACIONAL Y QUE, POR LO TANTO, QUIZÁS LAS ESTÁN ESCUCHANDO MIS PAISANOS. A ELLOS ME DIRIJO AHORA. RECUERDO, PRIMERO, A LOS MUERTOS HEROICAMENTE EN EPISODIOS FAMOSOS U OLVIDADOS. HABLO ASÍMISMO, A LA GENTE DE TACNA DE HOY. A LOS AGRICULTORES QUE CADA MADRUGADA EFECTÚAN EL MILAGRO DE REGAR SUS MINÚSCULAS Y PRODIGAS CHACRAS CON EL AGUA ESCURRIDIZA DEL LILIPUTIENSE RÍO CAPLINA. A LOS PIONEROS EN LA HAZAÑA DE EXTRAER DEL SUBSUELO EN LA ÁRIDA YARADA, EL LÍQUIDO ELEMENTO. A TODOS LOS QUE TIENEN SUS TAREAS Y OBLIGACIONES EN AQUELLA CIUDAD TAN LIMPIA Y TAN HERMOSA POR SUS FLORES, POR SU FRUTA Y POR SUS RECUERDOS. A LA BENEMÉRITA SOCIEDAD DE ARTESANOS DE AUXILIOS MUTUOS "EL PORVENIR" FUNDADA EN 1873 Y AÚN ACTIVA. A LOS JÓVENES, DOS DE LOS CUALES ME HONRARON, NO HACE MUCHAS SEMANAS, AL IZAR LA BANDERA EN EL PASEO CÍVICO. A LOS INTELECTUALES QUE, SIN APOYO OFICIAL SIGUEN IMPERTÉRRITOS DIRIGIENDO CON BRILLO UN MOVIMIENTO QUIZÁS SIN PARALELO EN EL PERÚ DE HOY. A LOS QUE DIGNAMENTE REPRESENTEN ALLA A LAS INSTITUCIONES TUTELARES DEL ESTADO. EN SUMA, PONGO, CON REVERENCIA, EN EL REZAGO DE MI TIERRA NATAL EL TESORO IMPALPABLE PERO ESPONTÁNEO, AUTÉNTICO Y PLETÓRICO DE RIQUEZA ESPIRITUAL REUNIDO AQUÍ HOY, Y PARA ESA TIERRA, CUANDO SE CUMPLEN 50 AÑOS, COMO ACABA DE DECIRLO ELOCUENTEMENTE EL CANCILLER, CUANDO SE CUMPLEN 50 AÑOS, EN QUE EL SACRIFICIO DE SUS HOMBRES, MUJERES Y NIÑOS CONTRIBUYÓ A QUE FUESE REINCORPORADA A LA PATRIA, PIDO UNA MÁXIMA, PERMANENTE Y CUIDADOSA PREOCUPACIÓN, TANTO EN LO MATERIAL COMO EN LOS DISTINTOS NIVELESDE LA ACTIVIDAD CULTURAL.

Así lo dijo don Jorge, y así lo evocamos hoy al vincular su nombre a Tacna, añadiendo como recuerdo final, sus palabras en la última entrevista que concediera, en la que al proponérsele un test de respuestas rápidas, al mencionársele Tacna contestó: "un pueblo al que le ha costado ser peruano pero al que no se le presta toda la atención que merece".

Percy Cayo Córdova

12-02-2003 